\title{
¿Qué hacer con los universalismos occidentales? Observaciones en torno al "giro
decolonial"
}

Cómo citar

este artículo en APA:

Castro-Gómez, S.

(2017). ¿Qué hacer

con los universalismos occidentales?

Observaciones en torno al "giro decolonial". Analecta Política, 7(13), 249-272.

Recibido:

15 de febrero de 2017 Aprobado:

15 de agosto de 2017

What to do with Western Universalisms? Some Remarks concerning the "Decolonial Turn"

$\mathrm{O}$ que fazer com os universalismos ocidentais? Observações em relação ao "giro decolonial"

\section{SANTIAGO CASTRO-GÓMEZ}

Doctor en Letras por la Johann Wolfgang Goethe-Universität de Frankfurt. Profesor en la Facultad de Filosofía de las Universidad Javeriana - Universidad Santo Tomás. Correo electrónico: scastro@javeriana.edu.co. orcid.org/ 0000-0003-40466916 Dirección Postal: Facultad de Ciencias Sociales - Carrera 5. No. 39-00 Edificio 95, Teléfono: 3208320. Ext. 5910. Oficina 404. Bogotá - Colombia. 


\begin{abstract}
["] Resumen
En círculos académicos de América Latina se afirma la tesis de que el propósito central de una "teoría decolonial" es la denuncia del eurocentrismo. Se piensa, además, que la "descolonización" de las ciencias sociales, el arte y la filosofía radica en recuperar el conocimiento ancestral de las comunidades indígenas o afro-descendientes. Finalmente, se dice que el propósito de una teoría crítica “desde América Latina” sería negar toda pretensión de universalidad. En este trabajo quisiera presentar algunos argumentos que cuestionan tales posiciones. En primer lugar, preguntaré si es posible pensar las identidades culturales en términos particularistas. Luego, abordaré el problema del eurocentrismo para dilucidar a qué tipo de fenómeno específico puede ser aplicable este término. Enseguida me moveré hacia el tema del universalismo, mostrando que la política emancipatoria no puede renunciar al gesto de la universalización de intereses*. Finalmente, quisiera articular algunas reflexiones en torno a la noción de "transmodernidad", desarrollada en América Latina por el filósofo argentino Enrique Dussel.
\end{abstract}

\title{
Palabras clave
}

Universalismo, particularismo, identidad cultural, descolonización, cultura latinoamericana.

\section{Abstract}

Some academic circles in Latin America support the idea that the main purpose of a "decolonial theory" is to denounce eurocentrism. Such circles also argue that "decolonization" of social sciences, art, and philosophy consists in the recovery of the ancient knowledge of indigenous and afro-descendant communities. Finally, they state that the purpose of a critical theory "pursued in Latin America" would consist in denying any aspiration for universality. In this paper, I would like to present some arguments that question such positions. First, I will ask if it is possible to consider cultural identities within particularism. Then, I will address the issue of eurocentrism in order to clarify to what kind of phenomena this term might apply. Afterwards, I will address the issue of universalism by showing that emancipation politics cannot give up the gesture of the universalization of interests. In the end, I would like to express some

* Todos estos argumentos se encuentran desarrollados con amplitud en (CastroGómez, 2015). 
thoughts concerning the idea of "transmodernism", which was developed in Latin America by the Argentinian philosopher Enrique Dussel.

\section{Key words}

Universalism, particularism, cultural identity, decolonization, Latin American Culture.

\section{Resumo}

Nos círculos acadêmicos da América Latina afirma-se a tese de que o propósito central de uma "teoria decolonial" e a denúncia do euro centrismo. Pensa-se, além, que a "descolonização" das ciências sociais, a arte e a filosofia, reside em recuperar o conhecimento ancestral das comunidades indígenas ou afrodescendentes. Finalmente, se assinala que o propósito de uma teoria crítica "desde América Latina” seria negar toda pretensão de universalidade. Neste trabalho eu quisesse apresentar alguns argumentos que põem em causa tais posiçôes. No primeiro lugar, perguntarei se é possível pensar as identidades culturais em termos particularistas. A seguir, abordarei o problema do euro centrismo, a fim de esclarecer o tipo de fenômeno especifico ao qual esse termo pode ser aplicável. Seguidamente, irei analisar o tema do universalismo, mostrando que a política emancipatória não pode prescindir do gesto da universalização de interesses. Finalmente, quisesse articular algumas reflexões em torno da noçâo de "transmodernidade", desenvolvida na América Latina pelo filosofo argentino Enrique Dussel.

\section{Palavras-Chave}

Universalismo, particularismo, identidade cultural, descolonizaçáo, cultura latinoamericana. 


\section{La imposibilidad del particularismo de las identidades}

La primera pregunta que quisiera plantear es si las identidades culturales pueden ser pensadas como particularidades puras, esto es, como fenómenos que se constituyen sólo en relación consigo mismos, con su propia tradición ancestral, y que existen con total independencia de sus relaciones con el exterior, a la manera de mónadas autosuficientes. De entrada, diré que la respuesta a esta pregunta debe ser negativa. ¿`Por qué razón? Porque no es posible comprender el sentido y la función de una práctica cualquiera si la abstraemos de la red de relaciones que la hace posible. No existe ninguna práctica que tenga sentido por si misma, con independencia de la posición y la función que ocupa en una red de relaciones diferenciales. Esta, me parece, es una de las lecciones básicas que aprendemos tanto de la deconstrucción de Jacques Derrida como de la analítica del poder de Michel Foucault. Derrida, recordémoslo, parte de la lingüística de Saussure para mostrar que todo acto significativo se define únicamente dentro de un sistema de diferencias. El signo no se define por unas propiedades esenciales, sino por las diferencias que lo distinguen de otros signos. Es decir que el signo no tiene identidad consigo mismo; la identidad plena del signo es algo que se le "escapa" constantemente, pues esta dependerá siempre de la posición diferencial de ese signo en el sistema de significaciones. Derrida nos dice que en un sistema de este tipo no puede pensarse algo así como una "armonía preestablecida" entre los elementos, es decir, un principio que regule la posición que ocupa cada uno de ellos en el sistema y establezca de antemano el tipo y el número de relaciones que establece con todos los demás elementos. Si esto ocurriera, lo que tendríamos sería un sistema cerrado, libre de diferencias, pero entonces quedaría cerrada también la posibilidad de la significación.

Foucault, por su parte, dice que toda comunidad humana se encuentra atravesada por relaciones de fuerza, lo que quiere decir que ninguna fuerza particular puede definirse con independencia del sistema de fuerzas que la constituye, bien sea como fuerza afectante o como fuerza afectada. Ningún elemento puede existir si no está referido a las relaciones de fuerza que establece con los demás elementos. Este modelo agonístico del poder apunta hacia la tesis de que ninguna formación social jamás podrá llegar a encerrarse en sí misma. El agonismo de las fuerzas engendra siempre nuevas y variadas configuraciones de poderes y contrapoderes, de modo que resulta imposible que una comunidad cualquiera pueda "completarse" y adquirir una identidad esencial. Siempre será una comunidad incompleta, pero no porque ontológicamente le falte algo, sino porque la dinámica de las fuerzas genera siempre nuevos pliegues y nuevas combinatorias diferentes de sus 
elementos. Es precisamente en este sentido que todas las comunidades humanas son históricas. Todo esto quiere decir, según Foucault, que no es posible buscar un "origen" último (Ursprung) que le dispense sentido y finalidad al sistema de fuerzas en su conjunto. Al igual que Derrida, Foucault afirma que la existencia de un "origen" anularía el juego agonístico de las fuerzas. Pero es precisamente esta falta de origen lo que hace que el juego de las fuerzas tenga siempre un final abierto, esto es, que exista una relación no determinable de antemano entre los poderes y los contrapoderes. Si existiera un "origen" que definiera de antemano esas relaciones, entonces no tendríamos juego alguno. Lo que tendríamos sería un sistema muerto, cerrado en sí mismo, en el que ninguna incitación mutua de las fuerzas sería posible.

Ahora bien, si pensamos las relaciones sociales como relaciones significativas, en el estilo de Derrida, o bien como relaciones de fuerza, en el estilo de Foucault, el resultado es exactamente el mismo: las identidades sociales no tienen esencia, puesto que la fijación última del sentido es una imposibilidad estructural de la cadena de relaciones. Tan sólo serán posibles fijaciones parciales y precarias, ya que las identidades sociales no pueden ser pensadas con independencia del sistema de relaciones diferenciales del que forman parte. No existen, por tanto, identidades que no sean relacionales, tal como lo concluyó también el filósofo argentino Ernesto Laclau:

Aceptemos por un momento la posibilidad de que la armonía preestablecida fuera posible. En tal caso, los varios particularismos no estarían en una relación antagónica entre sí, sino que coexistirían en una totalidad coherente. Esta hipótesis muestra claramente por qué el particularismo puro es, en última instancia, contradictorio. Porque si cada identidad está en una relación diferencial, no antagónica, con todas las demás identidades, la identidad en cuestión es puramente diferencial y relacional; en consecuencia, ella presupone no sólo la presencia de todas las otras identidades sino también el espacio global que constituye las diferencias como diferencias. Peor aún: como sabemos muy bien, las relaciones entre grupos se constituyen como relaciones de poder -es decir que cada grupo no es sólo diferente de los otros, sino que en muchos casos constituye esa diferencia sobre la base de la exclusión y la subordinación de los otros grupos. Ahora bien, si la particularidad se afirma a sí misma como mera particularidad, en una relación puramente diferencial con otras particularidades, está sancionando el statu quo en la relación de poder entre los grupos. Esta es exactamente la noción de "desarrollos separados" tal como la formulara el apartheid: sólo se subraya el aspecto diferencial, en tanto que las relaciones de poder en el que este último se basa son sistemáticamente ignoradas (Laclau, 1996, pp. 54-55). 
¿Qué hacer con los universalismos occidentales? ...

Lo que dice Laclau es que las identidades sociales no son esenciales, es decir que no se constituyen sólo en relación consigo mismas, con su propia tradición cultural, ni remiten tampoco a un origen (Ursprung), a un espacio ancestral "propio" que ofrecería, de una vez para siempre y sin relación con una exterioridad, los significados acerca de lo que un grupo "es". Tal posición, por desgracia bastante común en algunos círculos de izquierdas en América Latina, es políticamente conservadora, diría que incluso reaccionaria. Las luchas identitarias, sea cuales fueran (de género, raza, clase, orientación sexual, etc.), no pueden tener como objetivo político la afirmación de la propia identidad y al mismo tiempo verse a sí mismas como luchas progresistas, ya que con ello dejan intacto el sistema de relaciones que jerarquiza las identidades. Sancionan, como dice Laclau, el statu quo del sistema jerárquico inclusión/exclusión y reproducen, de este modo, la lógica del apartheid. Quien afirma una particularidad sólo puede hacerlo si reconoce, al mismo tiempo, el sistema relacional de fuerzas en el que esa particularidad se inscribe. Pues si la afirmación de la particularidad fuera el único principio aceptado de lucha, entonces la afirmación de cualquier particularidad debería ser igualmente válida, incluida, desde luego, la de aquellos grupos que han subordinado la identidad por la que se está luchando. Estamos, pues, frente a una paradoja insoluble.

Es claro entonces que la "identidad cultural" no es más que la cristalización temporal de ciertas relaciones de poder y no una esencia intemporal que pueda ser pensada con independencia de estas. No hay manera de que una comunidad particular (sea indígena, negra, gay, musulmana, lésbica) viva una existencia independiente del sistema de relaciones de poder que la ha constituido, así, como identidad subalterna. Es una ilusión creer que las comunidades subalternas viven como las mónadas de Leibniz, sin puertas y con ventanas abiertas hacia el mundo exterior. Por eso Laclau dice que una lucha por la transformación de la condición subalterna de estas comunidades tiene que incluir la transformación del sistema de relaciones desigualitarias a partir del cual estas comunidades son definidas como subalternas. No es posible cambiar una relación de poder simplemente aferrándose a la diferencia cultural, es decir, al particularismo de las identidades y dejar intocado el sistema de relaciones que trascienden esa particularidad. Quien lucha por cambiar su posición subalterna tendrá que cambiar también las relaciones de poder que han definido esa posicionalidad particular, lo que implica de manera necesaria aceptar que su identidad se verá también modificada. ${ }^{1}$ No se

1 Al respecto dice Laclau: "En lugar de invertir una relación particular de opresión/cierre en lo que tiene la particularidad concreta, invertir lo que hay en ella de universalidad - la forma de opresión y cierre como tal. La referencia al otro se mantiene también aquí, pero como la inversión tiene lugar al nivel de la referencia universal y no de los contenidos concretos del 
puede tener una cosa, sin tener también la otra. Modificar un sistema jerárquico de relaciones significa, de manera inevitable, modificar la particularidad de cada uno los elementos que se relacionan en ese sistema.

Tomemos el caso hipotético de una comunidad subalterna que se ubica a sí misma en una posición de completa exterioridad con respecto a la "cultura occidental" y reclama conocer la "verdad" de esa cultura (en tanto que es esencialmente diferente a los valores que unifican a esa comunidad subalterna). Aquí lo que tendríamos es la negación de la lucha política en nombre de un esencialismo cultural. ¿Por qué razón? Ya lo hemos visto: sólo hay política si primero se reconoce que entre los adversarios existe una relación de antagonismo. Pero cuando una de las partes niega (por la razón que fuese) la existencia de tal relación, poniéndose a sí misma en un lugar de exterioridad radical frente al sistema de relaciones antagónicas que ha constituido a unos como colonizadores y a otros como colonizados, a unos como superiores y a otros como inferiores, entonces la política ya no sería posible. La fórmula es simple: allí donde hay esencialismos no puede haber política, y allí donde hay política no puede haber esencialismos. La exterioridad, como veremos más adelante, únicamente puede entenderse como exterioridad relativa.

De todo esto podemos concluir que una posición teórica "decolonial" no es aquella que busca la recuperación de la identidad cultural de los pueblos colonizados. Tal recuperación no es más que una quimera, pues ha sido justo el sistema-mundo moderno/colonial el espacio en que se han constituido las identidades de cada uno de los elementos que entraron en esa matriz de relaciones jerárquicas. Aquello que Mignolo llama la "diferencia colonial" sólo tiene sentido en un sistema desigualitario de relaciones de poder y no debe ser pensada, por tanto, como una inconmensurabilidad de tipo cultural entre europeos y no europeos. Esto último nos conduciría directo a una especie de fundamentalismo culturalista de tipo conservador. $\mathrm{Si}$ tomamos, en cambio, la conquista de América como el momento de "emergencia" (Entstehung) de ese sistema diferencial de fuerzas, diríamos entonces que no hay una identidad indígena, negra o europea que sea previa a la consolidación de esa red geopolítica de relaciones. Lo que quiero decir es que las identidades son lo que son, únicamente a través de sus diferencias en una matriz de relaciones jerárquicas de poder que organiza la posición ocupada por cada una de ellas. Pretender la "conservación" de la identidad cultural de los pueblos colonizados, o bien su "retorno" a una matriz identitaria ancestral, poco tiene que ver con una política emancipatoria. Este tipo de representación, que afirma la diferencia, pero sacándola de la red de

sistema opresivo, las identidades tanto de los opresores como de los oprimidos son radicalmente modificadas" (Laclau, 1996, p. 62). 
¿Qué hacer con los universalismos occidentales? ...

antagonismos que la hace posible para contemplarla como un objeto impoluto y distante, no es otra cosa que una representación colonial.

\section{¿Qué es el "eurocentrismo"?}

Es precisamente en nombre de este particularismo estéril que muchos activistas y académicos de América Latina recurren frecuentemente a la sospecha de "eurocentrismo" y "colonialismo intelectual" como eje catalizador de sus luchas. No son pocos los que afirman que "pensar desde América Latina" significa pensar por fuera de los parámetros establecidos por la política moderna, ya que son específicamente europeos y se montan sobre la exclusión sistemática de las culturas no europeas (Bautista, 2014). En algunos circuitos teóricos de la región se viene imponiendo una especie de Abyayalismo que sustituye al Latinoamericanismo de las décadas anteriores, en el que se proclama un "desprendimiento" de la modernidad, incluidas las tradiciones críticas de la izquierda, para recuperar las "epistemes-otras" de los pueblos indígenas y afro-descendientes. Consideran, por tanto, "eurocéntrica" aquella posición que niega, en nombre de valores modernos (como la igualdad y la libertad), la posibilidad de regresar a un arché, a una comunidad originaria en la que imperan valores radicalmente diferentes a los modernos.

¿Qué tan válidos pueden ser estos argumentos? Para dilucidar esto, quisiera considerar en primer lugar la posición del filósofo Slavoj Žižek. El argumento del esloveno es claramente hegeliano. Es cierto que los poderes coloniales europeos irrumpieron con violencia en el mundo de las sociedades no europeas, alteraron sus costumbres y destruyeron el tejido cultural de su experiencia. Pero esto significa que la resistencia política frente a esta irrupción colonial debe echar mano del lenguaje del colonizador para llevar a cabo su lucha, en lugar de propugnar por un retorno a los lenguajes previos a la ocupación colonial. ¿Por qué razón? Porque sólo radicalizando la universalidad, es decir, universalizando su "punto de exclusión", podrá el movimiento descolonizador lograr sus objetivos. No lo conseguirá negando la universalidad y buscando un "retorno a los orígenes", un regreso a la situación pre-colonial, invocando el "rescate" de una identidad cultural olvidada. Esto equivaldría simplemente a reforzar la ideología en su expresión más reaccionaria: creer que es posible rasgar el velo de la negatividad y descubrir, más allá de ella, el secreto oculto de la reconciliación. A contrapelo de esto, el esloveno muestra que la lucha por la descolonización debe asumir plenamente la herencia europea, esto es, el gesto de la universalización, para, desde ahí, plantear sus demandas (Žižek, 2001). 
Žižek ilustra su punto con varios ejemplos. El más claro de ellos es el de los procesos de independencia poscolonial en el siglo XX, principalmente el de la India. Ante la crítica de muchos teóricos culturales indios de que el inglés les ha sido impuesto como lengua colonial y que la descolonización debería suponer un retorno a las lenguas nativas, el filósofo esloveno retoma el caso de los Dalits, aquellos sujetos tenidos como parias por el sistema tradicional de castas de la India. Justamente fueron ellos los que "no tenían parte" en ninguna de las castas, quienes reivindicaron el inglés como lengua nacional. Para los Dalits, el sistema colonial inglés creó las condiciones formales para que fueran vistos como sujetos jurídicamente iguales ante la ley. Antes de eso, en la situación pre-colonial, no gozaban de ningún derecho, sino que eran tenidos como un homo sacer (Žižek, 2014). Lo que este filósofo quiere decir es que la descolonización debe radicalizar la universalidad abstracta del legado colonial. No se trata, pues, en nombre de la descolonización, de liberarse de la universalidad (por considerarla un instrumento del colonizador), sino de apropiarse de ella para mostrar que esta universalidad es "incompleta", que ha dejado algo por fuera. La lucha no es entonces por desembarazarse de la universalidad, sino por encarnarla. Pues sólo cuando los que "no tienen parte" muestran que ellos son el punto que "niega" la universalidad abstracta, es cuando esa universalidad se torna realmente libertaria. En palabras de Žižek (2014), "sólo cuando los indios abrazan el ideal democrático-igualitario, ellos llegan a ser más europeos que los europeos mismos” (p. 136).

Otro ejemplo es el de Malcom X, el activista afroamericano de los años 60. ¿Por qué emplea esta $\mathrm{X}$ en su nombre de pila? Con ello quería indicar que había perdido definitivamente la identidad que le ligaba con sus ancestros esclavos y que no era posible un retorno a sus "raíces étnicas". Pero es esta ausencia de identidad la que le abre la posibilidad de reinventarse a sí mismo, luchando por una identidad más universal incluso que la reclamada por los blancos. La lucha política de los sujetos que, como él, no "tienen parte" en la sociedad, no consiste en "volver" a la particularidad del grupo étnico, a una comunidad orgánica situada mitológicamente "antes de la caída". Consiste, más bien, en apropiarse de la universalidad abstracta que los blancos han reservado para ellos y hacerla concreta mediante su "punto de exclusión", aquel elemento que esa universalidad dejó por fuera (Žižek, 2014). La universalidad sólo se hace efectiva cuando es apropiada por aquellos que fueron excluidos de la misma. La lucha de Malcom X no buscaba volver "más atrás" de la universalidad moderna, negándola en nombre de un retorno a los orígenes africanos de la identidad, sino llevarla "más allä" de los límites señalados por los esclavistas blancos. Se trata, entonces, de radicalizar la universalidad y no de abandonarla, como plantean hoy día muchos teóricos poscoloniales. Ya el propio Nelson Mandela se daba cuenta de que la supremacía 
¿Qué hacer con los universalismos occidentales? ...

blanca y la tentación del retorno a las raíces tribales, eran las dos caras de una misma moneda (Žižek, 2014).

Aunque no comparto con Žižek varios elementos de su crítica, concuerdo, sin embargo, en que la mejor forma de combatir el colonialismo y el eurocentrismo no es recluyéndose en los particularismos étnicos y negando la universalidad política por considerarla un instrumento en manos del colonizador. Al contrario, la lucha por la descolonización debe hacerse a través de la universalización de intereses. No se trata de una universalidad abstracta que niega la particularidad, sino de una universalidad concreta que se construye políticamente a través de la particularidad. Hacer lo contrario, negar toda universalidad con el objetivo de liberar las particularidades oprimidas por el colonialismo, no es sólo un gravísimo error político, sino que es un peligroso mecanismo de despolitización que el esloveno denomina "arquepolítica". Es el intento de regresar a un arché, a una comunidad originaria, homogénea, encerrada en sí misma e inmune frente a todo antagonismo. Una comunidad en la que no hay "síntoma" y no existe un punto de exclusión a partir del cual levantar una pretensión de universalidad. En su libro El espinoso sujeto, el filósofo presenta este problema como una clara línea divisoria entre la izquierda y la derecha: mientras que la derecha niega el universalismo y se contenta con la afirmación del particularismo puro, la izquierda, en cambio, sabe que no hay política emancipatoria sin universalismo y se opone a todo intento de mitologizar la particularidad (Žižek, 2001).

¿Cómo pensar entonces este problema de la particularidad y la universalidad? O, para utilizar el lenguaje de Žižek, ¿cómo entender la relación entre la universalidad abstracta y la universalidad concreta? Como ya vimos, algunos activistas dicen que el universalismo es tan sólo una estrategia para legitimar la superioridad cultural de Europa sobre el resto del mundo, sancionando de iure los privilegios obtenidos de facto a partir del saqueo que produjo la colonización. Es por esto que, en su opinión, la lucha contra la descolonización implica de manera imperiosa el abandono de la universalidad, ya que esta es tan sólo un invento perteneciente a la historia local y particular europea. Desde este punto de vista, la universalidad tiene solamente un carácter ideológico. Cualquier lucha política que apele a criterios universales pecaría de "eurocentrismo", porque elevaría a un carácter general lo que tan sólo vale para una cultura en particular. ¿Qué diremos frente a esto? Es verdad que, a través de la expansión colonial, Europa se empieza a ver a sí misma como la encarnación de funciones universales. Funciones que vienen definidas primero por el cristianismo (expansión colonial portuguesa y española) y más tarde por el racionalismo (expansión colonial inglesa y francesa). La cultura europea como encarnación de una forma humana universal que debía ser "comunicada" a todas las demás culturas, aun en contra de su propia voluntad. 
Las resistencias de las otras culturas eran vistas como prueba de su inferioridad, de su barbarismo, e incluso de su incapacidad constitutiva para acceder a lo universal. Aquí sin duda tienen razón las críticas que se han hecho al universalismo europeo desde posiciones feministas, decoloniales y poscoloniales. Pero, ¿conlleva todo esto la negación de la universalidad? Creemos que no, porque el problema que está en juego no es elegir entre lo universal y lo particular, sino comprender el tipo de relación que se da entre estos dos polos. No se trata de equiparar el eurocentrismo con la universalidad para después abandonar las dos cosas en nombre de la particularidad, sino de entender que eso que hoy llamamos "eurocentrismo" no es más que una forma especifica de plantear la relación entre universalidad y particularismo que procede de la ilustración (Aufklärung).

Para comprender este problema debemos acudir de nuevo al filósofo argentino Ernesto Laclau, quien en su libro Emancipación y diferencia reconstruye en tres momentos la compleja relación histórica entre lo universal y lo particular. El primer momento corresponde a la filosofía antigua clásica (Platón), en la que las relaciones entre ambos elementos son de mutua exclusión. Lo universal está dado de antemano y puede ser aprehendido por la razón, pero ello conlleva el abandono de toda particularidad, ya que esta no es sino la corrupción de la universalidad (Laclau, 1996). La relación entre los dos polos es esencialmente dicotómica: lo racional se opone a lo irracional y la verdad se opone a la apariencia, con lo cual se abren dos operaciones posibles: o bien lo particular se elimina a sí mismo para transformarse en el medio a través del cual la universalidad se manifiesta (que es la operación propiamente filosófica), o bien lo particular niega categóricamente lo universal y afirma su propio particularismo (que es la operación propiamente sofística). Dicho de otro modo, o eres un filósofo y puedes atrapar lo universal a través de la razón, o eres un sofista y te quedas atrapado en el mundo cavernícola de las particularidades. No existe mediación alguna entre estas dos posiciones. Tal mediación aparecerá sólo después con el cristianismo. Aquí lo universal no es accesible a través de una razón que se ha distanciado de lo particular, sino que se "encarna" en lo particular mismo. Es lo que ocurre en la Biblia cuando Dios revela su voluntad universal a los hombres mediante una serie de eventos esenciales que son opacos a la razón humana (Laclau, 1996). Entre lo universal y lo particular no existe entonces una relación de exclusión mutua, como ocurría en la filosofía antigua, ya que Dios aparece como mediador entre los dos polos. De este modo aparece la idea de que existen agentes privilegiados de la historia (los profetas, el pueblo elegido) que son el vehículo de lo universal. Sin embargo, entre lo universal y la particularidad que lo encarna no existe todavía una conexión de orden racional. Su relación depende exclusivamente de la voluntad de Dios y no del uso humano de la razón. 
¿Qué hacer con los universalismos occidentales? ...

Será apenas con el advenimiento del racionalismo que la conexión entre la universalidad y la particularidad que lo encarna se reviste de un carácter racional. Laclau muestra que el racionalismo moderno se deshace de la lógica cristiana de la encarnación, pues el papel de mediador entre lo universal y lo particular ya no lo asume Dios, sino la razón. Si todo lo que existe debe ser transparente a la razón (pretensión central de la Aufklärung), se hace necesario eliminar la opacidad entre la universalidad y la particularidad que la encarna, con lo que aparece la idea de un cuerpo que es, en sí y por sí mismo, universal. Aquí es donde se ancla no sólo el eurocentrismo (Europa como cuerpo universal), sino también la idea marxista de que el proletariado es una clase universal:

Lo universal había encontrado su propio cuerpo, pero éste era aún el cuerpo de una cierta particularidad. De tal modo, la europea era una cultura particular y, al mismo tiempo, la expresión -ya no la encarnación- de una esencia humana universal [...] Aquí el problema es que no había medios intelectuales para distinguir entre el particularismo europeo y las funciones universales que se suponía que él encarnaba, dado que el universalismo europeo había precisamente construido su identidad a través de la anulación de la lógica de la encarnación y, como consecuencia, de la universalización de su propio particularismo. De tal modo, la expansión imperialista europea tenía que ser presentada en términos de una función universal de civilización, modernización, etc. (Laclau, 1996, p. 50).

La vieja noción cristiana del "agente privilegiado de la historia" se une con la concepción iluminista de la relación entre lo particular y lo universal, para dar origen a eso que llamamos eurocentrismo. Europa se presenta como agente universal, bajo la convicción de que su cultura expresa principios incondicionales que derivan de privilegios epistemológicos y ontológicos. Lo universal no es resultado de la acción contingente de fuerzas antagónicas, sino la expresión trascendental de privilegios encarnados en actores específicos. Con lo cual queda claro que el problema del eurocentrismo no es la universalidad como tal, sino su concepción universalista del juego entre lo universal y lo particular. El eurocentrismo va de la mano con la tesis ilustrada de que existe un agente privilegiado de la historia cuyo cuerpo es expresión racional de una universalidad que lo trasciende. Entre el contenido universal y su expresión particular existe una relación de transparencia garantizada por la razón.

El eurocentrismo es, entonces, una forma peculiar de entender la relación entre lo universal y lo particular. Aquí, lo universal no se da a través de la particularidad, sino que existe con anterioridad a ella. Desde este punto de vista, el eurocentrismo es un término que refiere a una concepción clásica del universalismo 
y nada tiene que ver, por ejemplo, con reconocer que muchos de los adelantos técnicos, científicos y políticos que hoy día son patrimonio de la humanidad provienen de Europa. No hay que confundir una posición anti-eurocéntrica con la negación de toda universalidad, pues ello nos conduciría a un callejón sin salida. Debemos entender que la mejor forma de combatir el colonialismo y el eurocentrismo no es recluyéndose en las particularidades culturales y negando la universalidad por considerarla un instrumento en manos del colonizador. Al contrario, la lucha por la descolonización debe hacerse afirmando la universalidad. Pero no se trata, como veremos, de una universalidad abstracta que niega la particularidad (es decir del universalismo), sino de una universalidad concreta que se construye a través de la particularidad. Hacer lo contrario, negar toda universalidad con el objetivo de liberar las particularidades oprimidas por el colonialismo, no es sólo un gravísimo error político, sino que es un mecanismo de despolitización.

Filosóficamente hablando, ¿qué es entonces el eurocentrismo? Es una forma equivocada de entender la relación entre lo universal y lo particular. Lo universal es visto aquí como un conjunto de valores que preexisten a las relaciones establecidas por los actores sociales, y que son encarnados por uno de ellos en particular, en este caso en los europeos. Como puede verse, el eurocentrismo es la otra cara del particularismo extremo que estudiábamos en la sección anterior. Ambas posiciones imaginan una situación en la que un elemento en particular se sustrae al sistema de relaciones que lo hace posible y encarna una verdad definida tan sólo a partir de sí misma. En el primer caso se trata de imaginar una identidad cultural indígena o afro-descendiente no contaminada por el sistema moderno/colonial de relaciones; en el segundo, una cultura europea que encarna valores universalmente válidos para todo el planeta. Con Laclau diremos entonces que el eurocentrismo es un término que refiere a una concepción clásica del universalismo y nada tiene que ver con el reconocimiento de que la universalidad es un factor clave para entender la política. No hay que confundir entonces el universalismo con la universalidad, ni confundir tampoco una posición anti-eurocéntrica con el puro y simple chauvinismo de las particularidades.

\section{La universalidad como requisito de una política emancipatoria}

Como acabamos de ver, se ha hecho un lugar común la sospecha de que detrás de toda pretensión de universalidad se esconde un interés particular, y que la crítica 
¿Qué hacer con los universalismos occidentales? ...

al eurocentrismo radica en el abandono de todo universalismo por considerarlo un instrumento colonizador. La universalidad es vista como un fenómeno propio y singular de la historia local europea, que fue exportado violentamente hacia otros contextos culturales gracias a la colonización y opera, de este modo, como una institución imperialista. En esta sección quisiera discutir la pertinencia de tales argumentos.

Ante todo, hay que decir que cuando se habla de universalidad, quienes se ocupan de la filosofía política usualmente piensan en propuestas teóricas como las de Rawls y Habermas. Ambos filósofos entienden que no puede haber política sin apelar a un "punto de vista moral" en el que un acuerdo sólo podrá ser aceptado como legítimo si cumple una serie de requisitos procedimentales. Un acuerdo será universalmente válido cuando el procedimiento que lo hizo posible garantice que el resultado del mismo pueda ser aceptado por todos los participantes en la deliberación, con independencia de si ese resultado corresponde o no a sus intereses personales. Habermas en particular distingue entre el "discurso moral" y el "discurso ético". El discurso ético hace referencia a la deliberación en torno a lo que debe hacerse para llevar una "vida buena", para lo que se tendrán en cuenta las normas ancladas en la cultura particular de los hablantes, que en todo caso permanecen anclados en un contexto específico. El discurso moral, por el contrario, no apela a los valores culturales de los hablantes, sino que apela a juicios universales, pues su objetivo es la resolución imparcial y equitativa de los conflictos. Es decir que apelará a unos procedimientos de discusión que puedan ser aceptados como válidos por todos los participantes. Como se advierte, mientras que el discurso ético se ejerce siempre en un contexto específico, en el ethos de una comunidad histórica en particular, el discurso moral aspira a un reconocimiento universal de sus prescripciones, con total independencia de los ethoi particulares. La universalidad de la que aquí se habla no corresponde entonces a contenidos específicos, sino a los procedimientos que han de tenerse en cuenta para establecer esos contenidos.

No es extraño que este tipo de universalismo haya generado críticas provenientes sobre todo del feminismo y de la teoría poscolonial. Se sospecha que bajo esta razón universal se esconden siempre los intereses particulares de un sujeto varón, heterosexual, blanco, europeo, burgués, imperialista, de clase media, etc. El sociólogo puertorriqueño Ramón Grosfoguel nos dice, por ejemplo, que en tales universalismos "el sujeto epistémico no tiene sexualidad, género, etnicidad, raza, clase, espiritualidad, lengua ni localización epistémica en ninguna relación de poder, y produce la verdad desde un monólogo interior consigo mismo, sin relación con nadie fuera de sî" (Grosfoguel, 2007, p. 64). El universalismo sería 
tan sólo una particularidad más, un ethos que se postula como universal gracias a los privilegios que obtiene este sujeto epistémico de la dominación (colonial, machista, burguesa, capitalista) ejercida sobre otros.

Grosfoguel sospecha con razón que los "universalismos occidentales" son la otra cara de un eurocentrismo que legitima la superioridad de Europa sobre los pueblos sometidos a su dominio colonial. El universalismo corresponde a una encarnación cultural concreta (Europa), a un conjunto de valores dados a priori que preexisten a la política y que son usados como arma para someter a otras culturas y formas de vida tenidas como "bárbaras". En esto concordamos plenamente con Grosfoguel, pero el problema es la conclusión que muchos activistas y académicos sacan de esta crítica: se argumenta que toda pretensión de universalidad debe ser abandonada por completo, con el propósito de procurar la liberación de las particularidades sometidas. De un rechazo (correcto) al universalismo, se pasa sin más a un rechazo (incorrecto) a la universalidad como gesto fundamental de la política emancipatoria. El resultado de esto, como veremos enseguida, es la incapacidad de articular una voluntad común que vaya más allá de los particularismos. La universalidad no preexiste a las prácticas articulatorias que la hacen posible (en esto se distingue del universalismo), sino que es un efecto de las mismas. Por ello, como decía, estoy de acuerdo con Žižek cuando afirma que la universalización de intereses es el gesto político por excelencia.

Pero, ¿cómo se produce esta universalización de intereses? Tal vez sea Rancière quien con mayor claridad vislumbra este problema. De él toma Žižek la idea de que los "sin parte" (el elemento sintomático de la sociedad) pueden asumir la voz de todos y cuestionar de forma radical el orden existente. ¿Qué significa esto? Que en toda sociedad hay "sujetos flotantes" que no encajan en el ordenamiento que esa sociedad considera útil, normal, funcional o deseable. Son entonces los "parias" de esa sociedad, aquellos cuya voz "no cuenta" en el reparto de lo sensible. El momento propiamente político es aquel en el que esos sujetos flotantes establecen un litigio frente al ordenamiento que los excluye. Pero atención: lo que cuestionan no es la exclusión que ellos en particular experimentan, sino el ordenamiento mismo en el que esa exclusión tiene lugar. No piden ser incluidos en el mismo orden que les excluye ("queremos tener una parte en ese orden"), sino cambiar las reglas que son válidas para todos ("queremos otro orden"). De modo que, según el filósofo francés, la función política de los "sin parte" es "poner constantemente en juego lo universal bajo una forma polémica" (Rancière, 2007, p. 90). Cuando esos sujetos flotantes "toman la palabra" (algo que supuestamente no "pueden" hacer, ya que se les considera inferiores), en realidad no están hablando por ellos mismos sino por todos. Lo que cuestionan no es tal o cual regla en particular que debe ser cambiada, 
¿Qué hacer con los universalismos occidentales? ...

sino la totalidad de las reglas de juego que organizan desigualitariamente la sociedad. Su voz, en este sentido, es universal. No están litigando por la desigualdad en particular que vale para ellos, sino por la desigualdad que vale para todos.

Rancière (2007) menciona como ejemplo el caso de "la muchacha negra que un día de diciembre de 1955, en Montgomery (Alabama), decidió permanecer en su lugar en el autobús" (p. 89). Cuando Rosa Parks hace lo que supuestamente no debía hacer (un negro no puede sentarse en el lugar del autobús que corresponde sólo a los blancos), no estaba exigiendo un derecho para ella, o para la comunidad negra en particular, y ni siquiera para los habitantes de Estados Unidos, sino para todos los que en cualquier parte del mundo son tratados desigualmente en las distintas jerarquías que componen el "orden social": jerarquías de clase, género, edad, orientación sexual, trabajo, educación, política, etc. En cada una de estas jerarquías siempre juega una distinción entre aquellos que tienen parte y aquellos que no la tienen. De tal modo que cualquiera de los "sin parte" en cualquiera de esas jerarquías de poder, podría levantarse y decir: "yo soy Rosa Parks". Nótese además que la universalidad que invoca ella no es abstracta (basada en los Derechos Humanos que dicen "todos los hombres son iguales"), sino que es concreta, pues -como diría Žižek- universaliza una particularidad. Al sentarse en el lugar "equivocado" del autobús, Rosa Parks está diciendo: "aunque soy mujer y soy negra, me considero igual a todos los que se sientan aquí". Eleva de este modo una pretensión de igualdad que no habla en nombre de una particularidad (las mujeres negras), sino de un nosotros universal.

Nótese entonces que la presuposición de igualdad es justo el principio democrático que invocan los "sin parte" para articular una política emancipatoria. Sus reclamos no hacen énfasis en el hecho de la diferencia (soy mujer, negra, pobre, lesbiana, golpeada, etc.), sino en la condición de desigualdad. Al hacer lo que se supone que no puede hacer (alguien que ocupa un lugar inferior en una jerarquía de poder no puede "igualarse" con los que ocupan lugares superiores), Rosa Parks se apropia de aquello que se le niega y eleva una pretensión de universalidad que vale no sólo para ella, sino para todos los que son inferiorizados en cualquier otra jerarquía de poder. Lo cual significa que el combate a tales jerarquías no podrá hacerse en nombre de la diferencia y la particularidad, sino en nombre de la igualdad que invocan de manera abstracta los propios dominadores en sus constituciones democráticas. Como bien lo vio Žižek, la política emancipatoria radica en convertir esa universalidad abstracta en una universalidad concreta.

La negación de la universalidad en nombre del particularismo de las luchas no es entonces el camino para una política decolonial, tal como argumentan hoy 
día muchos activistas. No es posible hacer política sin el gesto emancipatorio de la universalización de intereses pues, de otro modo, la política se reduciría a la exaltación de los particularismos. Y este gesto, como ya vimos, no es solo filosóficamente cuestionable, sino que es políticamente conservador. La crítica a la universalidad abstracta del eurocentrismo no supone la negación de la universalidad, sino el paso de la universalidad abstracta a la universalidad concreta, tal como lo mostró Žižek. El eurocentrismo defiende ciertamente una universalidad abstracta despojada ilusoriamente de todo contenido, que se postula, sin embargo, como fundamento de todos los contenidos. La universalidad concreta, por el contrario, se produce a través de su síntoma, es decir, por medio de aquellos contenidos particulares que han sido negados por la universalidad abstracta. Más exactamente, por medio de la articulación de las particularidades que han sido dejadas "sin parte" en las diferentes jerarquías de poder que organizan la sociedad. ${ }^{2}$ Esos contenidos particulares, en lugar de afirmarse en su propia particularidad, deben ser "negados" equivalencialmente para que puedan insertarse en una forma hegemónica con pretensiones universales. Ya se ve entonces: no se niega la universalidad como tal, sino tan sólo la negación que la universalidad abstracta había establecido frente a determinados contenidos particulares.

Finalicemos esta sección diciendo que si lo que busca una lucha decolonial es afirmar las particularidades excluidas en cada una de las jerarquías de poder (sean estas de raza, clase, género, nación u orientación sexual), entonces ha renunciado de entrada a la política y caído en brazos de un multiculturalismo que ofrece a cada particularidad lo que necesita para reconocer su "identidad". Una política emancipatoria no es aquella que lucha por el reconocimiento de las formas de vida particulares, sino una que recurre a la universalización de intereses para combatir el "marco" que organiza desigualitariamente la sociedad. Pues, en últimas, es el mercado capitalista el que hoy día permite que cada particularidad pueda gozar de su estilo de vida. Hay productos de todo tipo para la comunidad gay y para las lesbianas, hay tiendas especializadas en música étnica, hay ropa y emblemas para los punks, mercados de artesanías indígenas, restaurantes de comida vegetariana, especies provenientes de la India, de Tailandia, etc. Así las cosas, una lucha emancipatoria no es aquella que renuncia a la universalidad con el argumento de que toda universalidad es eurocéntrica y colonialista. Es, por el contrario, una que rechaza el universalismo eurocéntrico en nombre de la universalidad política, pues

2 En mi opinión son cinco las jerarquías de poder que organizan desigualitariamente las sociedades contemporáneas: hay jerarquías de raza, clase, género, nación y orientación sexual. Las luchas políticas emancipatorias tendrán que ser entonces interseccionales, lo cual conlleva la articulación hegemónica de las particularidades excluidas en cada una de las cadenas. 


\section{6 | Santiago Castro-Gómez \\ ¿Qué hacer con los universalismos occidentales? ...}

sabe que su objetivo último es el combate contra la desigualdad y la dominación, donde quiera que estas se manifiesten. Afirmar, por el contrario, el particularismo de las identidades equivale a renunciar a la universalización de intereses, es decir, al gesto político por excelencia, tal como lo muestran tanto Žižek como Rancière y Laclau. Equivale a dejar la puerta abierta al multiculturalismo de las identidades, en las que las luchas políticas se mueven cómodamente al interior del marco desigualitario que organiza la sociedad, pero sin cuestionarlo jamás.

Desde este punto de vista, lo universal no tiene contenidos necesarios, sino que todos ellos son "puestos" de manera contingente a través de operaciones políticas. Lo cual quiere decir que lo universal no es una forma común a todos los humanos encarnada en un actor particular (Europa), sino una aspiración que debe ser "llenada" parcialmente a través de las luchas políticas. Es decir que no es un procedimiento que precede a la discusión política y la regula (como en Rawls y Habermas), sino un efecto contingente de operaciones equivalenciales (como en Laclau). Así las cosas, resulta claro que un llamado al particularismo extremo, tal como se da por ejemplo en las políticas de la diferencia en Europa y los Estados Unidos, pero también en ciertas concepciones abyayalistas en América Latina, no aporta mucho a las luchas progresistas. ${ }^{3}$ Insistimos: no es posible ningún tipo de política emancipatoria sin la universalización hegemónica de intereses. Negar la universalidad no es entonces el camino adecuado para superar el eurocentrismo.

\section{Transmodernidad}

Hemos venido argumentando que una política emancipatoria no es aquella que se repliega en la reconstitución de los tejidos comunitarios particulares porque se pone de espaldas a la transformación de las relaciones de poder que han subalternizado a esas particularidades. Pero entendámonos: esto no significa en absoluto que los valores anclados y vividos en esas comunidades particulares no sean importantes a la hora de pensar una política emancipatoria de izquierdas en América Latina. Para evitar esta lectura equivocada me parece importante considerar la

3 He acuñado la categoría "abyayalismo" en mi libro Revoluciones sin sujeto (Castro-Gómez, 2015) para referirme a las posiciones que propugnan por una "revitalización" de los valores de las culturas nativas previas a la colonización, como si tales valores hubieran permanecido en una exterioridad absoluta frente a las relaciones de poder que los subalternizaron. El abyayalismo es entonces la ilusión de que es posible sustraerse a las relaciones dominantes que definen la posición de las distintas particularidades en un sistema jerárquico de clasificación de las poblaciones (eso que Quijano denomina la "colonialidad del poder"). 
categoría "transmodernidad", tal como ha venido siendo utilizada por el filósofo argentino Enrique Dussel. ${ }^{4}$ De entrada digamos que la noción se mueve en dirección contraria a lo que muchos grupos de intelectuales y activistas entienden hoy día por "descolonización". Operando con la curiosa idea de que la modernidad en su conjunto tiene una "lógica profunda" que es el colonialismo, es decir, que todo despliegue modernizador es de suyo colonialista y no puede serlo de otro modo, tales activistas se precipitan en una actitud radicalmente anti-moderna y políticamente conservadora. ${ }^{5}$ Según ellos, descolonizarse significa escapar de la modernidad (identificada con el genocidio de los pueblos, el "epistemicidio" y la destrucción cultural), replegarse en las "epistemologías" sobrevivientes propias de aquellos pueblos que no fueron coaptados enteramente por la modernidad (comunidades indígenas y negras para el caso de las Américas), pues allí se encuentran las semillas de "otro mundo" muy distinto al occidental. ${ }^{6}$ Vincularse orgánicamente con esas "epistemes-otras" es tenido por tales intelectuales como el acto político emancipador por excelencia. No obstante, la política que ofrece Dussel tiene en realidad muy poco que ver con esta visión esencialista y reduccionista. El filósofo argentino no es antimoderno sino transmoderno. ¿Qué significa esto?

Al igual que los otros miembros del grupo modernidad/colonialidad (Mignolo, Quijano, Grosfoguel, yo mismo), Dussel parte de la tesis de que la modernidad es un fenómeno histórico que tiene un momento "intrauterino" (por así decirlo) con la constitución de la burguesía hacia finales de la edad media europea, pero que adquiere su perfil definitivo gracias a la conquista de América y la creación del mercado mundial con la expansión colonial de las potencias europeas (lo que teóricos marxistas como Immanuel Wallerstein han llamado el "sistema-mundo moderno"). Este sistema mundial coloca por primera vez juntas, pero en relación asimétrica, a una gran cantidad de "culturas" que antes habían

4 No es Dussel quien habla primero de "transmodernidad". Ya lo había hecho antes la feminista posmoderna española Rosa María Rodríguez Magda (1989) en su libro La sonrisa de Saturno. Hacia una teoría transmoderna. Pero su uso del concepto es muy diferente al que hace Dussel.

5 Muchos de estos activistas toman como referencia al grupo modernidad /colonialidad, pero en realidad nadie de este grupo (hasta donde yo recuerdo) sostuvo jamás una idea semejante. Lo que se dijo es que la modernidad y la colonialidad son dos caras distintas de una misma moneda (la constitución en el siglo XVI del "mercado mundial" al que se refiere Marx en el Manifiesto), pero no que la modernidad es un "efecto de superficie" cuya "lógica oculta" es la colonialidad. Ningún miembro del grupo dijo jamás que la modernidad se reduce a la colonialidad (!).

6 Hay que decir, sin embargo, que la obra temprana de Dussel (en los años 70) favorecía esta actitud anti-moderna, pues presentaba a la modernidad como una "totalidad opresora" en su conjunto. Actitud que por fortuna será posteriormente moderada por el propio Dussel en la medida en que se deja interpelar por los textos de Marx. 
¿Qué hacer con los universalismos occidentales? ...

vivido separadas unas de otras por establecer sobre ellas la hegemonía de una concepción primero fue cristiana y señorial (siglos XVI-XVII), y luego racionalista y capitalista (siglos XVIII-XX) de entender la vida, el conocimiento, la naturaleza y las relaciones sociales. Dussel se refiere específicamente a culturas milenarias como las provenientes de India, China, el mundo árabe y el mundo indígena precolombino (Dussel, 2015).

Nótese que la colonización en Dussel (2015) no se reduce al "genocidio" y/o la "occidentalización" completa de pueblos y culturas (que sin duda ocurrió en más o menos casos), sino que es, ante todo, el establecimiento de una hegemonía cultural. Esto quiere decir que las culturas de esos pueblos no fueron destruidas (su propio peso histórico milenario lo impedía), sino que amplios pliegues de su "sentido común", de su "mundo de la vida" (Lebenswelt), fueron transformados con la introducción del cristianismo, la ciencia moderna, la modernización político-cultural y, sobre todo, el capitalismo. Pero esto significa también que tales pliegues han permanecido en una "exterioridad relativa" con respecto al significado que todos estos procesos adquirieron en Europa. Aquí se muestra el alcance del concepto gramsciano de "hegemonía" utilizado por Dussel. La colonización conlleva el establecimiento de un "consenso" tácito entre los valores occidentales traídos con la colonización europea y los valores propios de las culturas colonizadas, provenientes de su mundo ancestral premoderno. Pero Dussel tiene claro que esos valores ancestrales no han permanecido inalterados con el advenimiento de la modernidad (a la que fueron incorporados por el colonialismo), sino que se han transformado junto con ella. No hay ningún tipo de esencialismo cultural en Dussel, similar al que se evidencia en las posiciones "abyayalistas" que mencionamos anteriormente. La exterioridad de las culturas colonizadas es solamente relativa y no absoluta frente a los procesos de modernización. Dussel tiene claro que la modernidad es un fenómeno irreversible del cual ninguna cultura en el planeta tierra puede ni podrá sustraerse por entero, tal como lo entrevió Marx.

¿Qué significa entonces la "transmodernidad"? Esta noción apunta hacia el modo en que ese proceso mundial de modernización económica, política y cultural puede ser "asimilado" dialécticamente desde las diferentes culturas subalternizadas por la expansión colonial europea. Significa atravesar la modernidad, pero desde "otro lugar", que es justamente el de aquellos que fueron "negados" por la modernización hegemónica euro-norteamericana (posicionada como "centro" de la modernidad). En términos de Marx, la transmodernidad sería entonces la "negación de la negación", es decir, la asimilación creativa y emancipadora de la modernidad realizada desde historias locales. Se trata de una modernidad vivida desde la exterioridad relativa que niega su forma occidentalista y eurocentrada. Una 
modernidad, en últimas, descolonizada. Pero tal descolonización no remite, como decimos, a un proyecto antimoderno, sino a un proyecto crítico y emancipatorio frente a las instituciones desarrolladas por la modernidad misma. Desde esta perspectiva, Dussel entiende la transmodernidad como un proyecto político, económico, social y cultural que marcará una nueva fase de la historia mundial. Un proyecto que, según él, será impulsado por "intelectuales orgánicos" situados en medio (Borderthinking) de su propia cultura subalternizada y la modernidad eurocentrada. Son intelectuales poscoloniales, aquellos que viven "entre dos mundos", quienes pueden establecer las mediaciones culturales necesarias entre la modernidad occidental y los valores de las culturas negadas por esta durante la expansión colonial y propiciar, de este modo, la "negación de la negación". Nótese entonces: la transmodernidad no es una operación de "retorno" a los valores de las culturas "nativas" antes de la colonización, sino una "problematización" que tiene dos caras: de un lado, la modernidad eurocentrada es reinterpretada desde las historias locales negadas por la colonización; pero del otro lado, y al mismo tiempo, la propia cultura subalterna, modificada ya indefectiblemente por los procesos de modernización, debe ser reinterpretada críticamente (Dussel, 2015). No hay entonces en Dussel ningún amago de subalternismo, posición que, por desgracia, se ha expandido como un virus en no pocos sectores intelectuales de América Latina. ${ }^{7}$

Comparto muchos de los análisis que hace Dussel a este respecto y a diferencia de los subalternistas, entiendo la descolonización en el sentido "transmoderno" que él señala. Sin embargo, quisiera realizar algunas observaciones críticas antes de finalizar este trabajo. La primera tiene que ver con su noción de "núcleo éticomítico", categoría tomada de Paul Ricoeur, que le sirve a Dussel para pensar aquello que define no sólo esta o aquella cultura en particular, sino la cultura en general (Dussel, 2015). ${ }^{8}$ Su tesis parece ser que la religión forma parte del "núcleo ético-mítico" presente en todas las culturas. Y sobre la base de esta ontología de la cultura es que Dussel pone el proyecto transmoderno. En el fondo late la creencia de que esos "intelectuales orgánicos" de las culturas subalternas se hallan vinculados de algún modo a las "grandes religiones" de la humanidad: el Budismo, el Hinduismo, el Islam, el Cristianismo. El diálogo transmoderno sería entonces un diálogo entre intelectuales críticos vinculados con las grandes tradiciones religiosas. De ahí su énfasis en la necesidad del diálogo entre los teólogos y los filósofos, como lo deja ver en el apéndice de su libro Filosofias del Sur.

7 Para una crítica del "efecto Foucault" en algunas posiciones subalternistas, véase (CastroGómez, 2016).

8 Ya Dussel ha disertado ampliamente sobre esta noción en otros libros. Véase por ejemplo (Castro-Gómez, 2006) 
Quisiera articular una breve reflexión a este respecto. Hay por lo menos cuatro instituciones fundamentales nacidas de la modernidad que necesitamos reinscribir hoy en un escenario transmoderno: la ciencia, el Estado de derecho, la democracia y la crítica. Creo, junto con Dussel, que es posible una transmodernización de estas instituciones y es en este sentido preciso que entiendo el "giro decolonial". La primera de ellas es la ciencia. No podremos garantizar la vida de las poblaciones (como dice Dussel) sin el concurso de la ciencia moderna, enriquecida desde luego con aportes provenientes de las medicinas no occidentales (el llamado "diálogo de saberes"). Rechazar de plano la medicina moderna (por considerarla "imperialista" o "atea") sería un acto de oscurantismo similar al derribamiento de las estatuas de Buda por parte de los Talibanes.

La segunda institución (imprescindible por ahora) es el Estado de derecho, que querámoslo o no, continúa siendo el marco básico de la política, aún a pesar de las pretensiones levantadas en los últimos años por los movimientos antiglobalización y otros grupos autogestionarios. En Bolivia, por ejemplo, el Estado de derecho no desaparece, sino que integra y reconoce diferentes formas de autoridad y gobierno comunitario, lo que produce un constitucionalismo de nuevo tipo, como bien lo muestra Boaventura de Sousa Santos. ${ }^{9}$ La tercera institución es la democracia, entendida como un imaginario político en el que la igualdad y la libertad son valores universalizables, susceptibles de ser extendidos hacia toda la comunidad. Estos valores no tienen por qué reñir con formas ya existentes de igualitarismo y participación ancladas en diferentes culturas (como la de los caracoles zapatistas a la que hace referencia Dussel), pero debemos entender que la democracia supone el rechazo de todas las jerarquías de poder que organizan desigualitariamente la sociedad, así estas formen parte de las "tradiciones culturales" de una comunidad. Finalmente, la cuarta institución que considero básica para una situación transmoderna es la crítica. Con ello me refiero al ejercicio de la problematización, la desnaturalización de lo dado, el cuestionamiento del "sentido común" a través del arte, el debate de ideas, la filosofía, etc. Pero, aun en una hipotética situación transmoderna, la reinscripción no eurocéntrica de estas instituciones conllevará, de todos modos, el desafío de asumir la incompletud ontológica que ellas arrastran consigo. ${ }^{10}$

Dicho de otro modo: la transmodernidad no puede significar remitir la ciencia, el Estado de derecho, la democracia y la crítica racional a las certezas incuestionadas de un fundamento último, con el argumento de que tales certezas

9 Véase (Sousa, 2010)

10 Sobre este tema, véase (Castro-Gómez, 2015) 
forman parte de la "identidad cultural" de otros pueblos y de que es necesario "inculturar" ahí tales instituciones. Digo esto porque me parece que la categoría dusseliana de "transmodernidad" es heredera del gran debate que se dio en América Latina, sobre todo en círculos de la Iglesia Católica hacia la década de 1970, en torno a la necesidad de "inculturar" el evangelio. A raíz del Concilio Vaticano II, los teólogos reflexionaban sobre el modo en que la liturgia católica (largamente desarrollada en Europa) podría vivirse de una forma no eurocéntrica en contextos culturales como el asiático, el africano y el latinoamericano. Esta discusión, que puede ser válida para entender el problema de la interculturalidad religiosa (en el que en todo caso no se cuestiona el tema del fundamento último), me parece algo limitada para entender el modo en que algunas instituciones modernas (cuyo funcionamiento depende de la ausencia de fundamento último) pueden ser experimentadas en contextos culturales no occidentalizados. Por eso afirmo que no debemos entender la transmodernidad como una simple "inculturación" de la modernidad en contextos culturales no europeos.

\section{A manera de conclusión}

Corren días difíciles para la humanidad en su conjunto. La extrema derecha parece estar logrando la hegemonía cultural y política en importantes naciones del primer mundo y también en América Latina. Es muy importante comprender que la mejor estrategia para combatir esta tendencia no es el repliegue en las acciones comunitarias, sino la lucha por democratizar los valores anclados en el sentido común de las sociedades y por recuperar la soberanía de las instituciones públicas. No significa esto que la reconstitución de los tejidos comunitarios no sea importante para avanzar en esta lucha. Lo es, y mucho. Pero sería un error dar por perdida la lucha por la hegemonía política de las instituciones públicas en nombre de una "descolonización" que apunta hacia el subalternismo y el autonomismo. Debemos entender que no hay soluciones exclusivamente comunitarias para los problemas de sociedades complejas como las nuestras y que la construcción hegemónica de una voluntad común es lo único que puede ofrecernos esperanzas en medio del desierto. 


\section{Referencias}

Castro-Gómez, S. (2006). Filosofía de la cultura y la liberación. México: Universidad Autónoma de la Ciudad de México.

Castro-Gómez, S. (2015). Revoluciones sin sujeto. Slavoj Zizek y la crítica del historicismo posmoderno. Madrid / México: Akal

Castro-Gómez, S. (2016). Historia de la gubernamentalidad II. Filosofía, cristianismo y sexualidad en Michel Foucault. Bogotá: Siglo del Hombre Editores.

Laclau, E (1996). Universalismo, particularismo y la cuestión de la identidad, en Emancipación y diferencia. (pp. 54-55). Buenos Aires: Ariel.

Bautista, J. (2014). ¿Qué significa pensar desde América Latina? Madrid: Akal.

Žižek, S. (2001). El espinoso sujeto. El centro ausente de la ontología política. Barcelona: Paidós.

Žižek, S. (2014). Absolute Recoil. Towards a New Foundation of Dialectical Materialism. London: Verso.

Grosfoguel, R. (2007). "Descolonizando los universalismos occidentales: el pluriversalismo transmoderno decolonial desde Aimé Césaire hasta los zapatistas". En: CastroGómez, S y Grosfoguel, R. (Ed.). El giro decolonial. Reflexiones para una diversidad epistémica más allá del capitalismo global. Bogotá: Universidad Central, Instituto Pensar: Siglo del Hombre Editores.

Rancière, J. (2007). El odio a la democracia. Buenos Aires: Amorortu Editores.

Sousa, B. (2010). Refundación del Estado en América Latina. Perspectivas desde una epistemología del Sur. Quito: Ediciones Abya Yala.

Dussel, E. (2015). Filosofías del Sur. Descolonización y transmodernidad. México: Akal. 